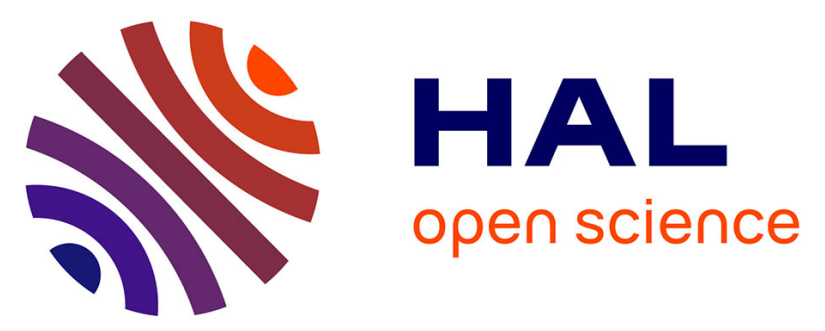

\title{
In situ 3D characterization of high temperature fatigue damage mechanisms in a cast aluminum alloy using synchrotron X-ray tomography
}

Sébastien Dezecot, Jean-Yves Buffiere, Alain Köster, Vincent Maurel, Fabien Szmytka, Eric Charkaluk, Nora Dahdah, Ahmed El Bartali, Nathalie Limodin, Jean-Francois Witz

\section{To cite this version:}

Sébastien Dezecot, Jean-Yves Buffiere, Alain Köster, Vincent Maurel, Fabien Szmytka, et al.. In situ 3D characterization of high temperature fatigue damage mechanisms in a cast aluminum alloy using synchrotron X-ray tomography. Scripta Materialia, 2016, 113, pp.254-258. 10.1016/j.scriptamat.2015.11.017 . hal-01255815

\section{HAL Id: hal-01255815 \\ https://hal.science/hal-01255815}

Submitted on 15 Jul 2021

HAL is a multi-disciplinary open access archive for the deposit and dissemination of scientific research documents, whether they are published or not. The documents may come from teaching and research institutions in France or abroad, or from public or private research centers.
L'archive ouverte pluridisciplinaire HAL, est destinée au dépôt et à la diffusion de documents scientifiques de niveau recherche, publiés ou non, émanant des établissements d'enseignement et de recherche français ou étrangers, des laboratoires publics ou privés. 


\title{
In situ 3D characterization of high temperature fatigue damage mechanisms in a cast aluminum alloy using synchrotron X-ray tomography
}

\author{
Sebastien Dezecot ${ }^{\text {a,b,c,*, Jean-Yves Buffiere }}{ }^{\mathrm{a}}$, Alain Koster ${ }^{\mathrm{b}}$, Vincent Maurel ${ }^{\mathrm{b}}$, Fabien Szmytka ${ }^{\mathrm{c}}$, \\ Eric Charkaluk $^{\mathrm{d}}$, Nora Dahdah ${ }^{\mathrm{d}, \mathrm{e}}$, Ahmed El Bartali $^{\mathrm{d}, \mathrm{e}}$, Nathalie Limodin ${ }^{\mathrm{d}}$, Jean-Francois Witz ${ }^{\mathrm{d}}$ \\ a INSA-Lyon, MATEIS, CNRS UMR 5510, 69621 Villeurbanne, France \\ b MINES ParisTech, PSL Research University, MAT - Centre des matériaux, CNRS UMR 7633, BP87 91003 Evry, France \\ c PSA Peugeot Citröen, Direction de la Recherche et de l'Innovation Automobile, Route de Gisy-78943, Vélizy-Villacoublay Cedex, \\ France ${ }^{\mathrm{d}}$ Laboratoire de Mécanique de Lille (LML), CNRS UMR 8107, Cité Scientifique, 59650 Villeneuve d'Ascq, France \\ e Ecole Centrale de Lille, 59650 Villeneuve d'Ascq, France
}

\begin{abstract}
Fatigue tests were performed at $250^{\circ} \mathrm{C}$ on a cast AlSi7Cu3Mg aluminum alloy and monitored with Synchrotron in situ X-ray tomography in order to understand the micro-mechanisms of crack initiation and propagation. The analysis of the 3D images reveals that internal shrinkage pores are responsible for the main crack initiation. Crack propagation is mainly due to the complex and highly interconnected network of hard particles of the eutectic regions.
\end{abstract}

Automotive engine evolutions tend to increase thermal-mechanical cyclic loading on the cylinder heads [1], [2], [3]. Due to its excellent castability characteristics and good mechanical properties, the AlSi7Cu3Mg aluminum alloy (close to A319 alloy), with a high Silicon and Copper contents, is a good choice to produce these components. The Lost Foam Casting (LFC) process, which enables easy and cheap casting of complex geometries, is being considered in order to replace the traditional Die Casting (DC) process. However, the lower cooling rates associated with the LFC process [4] result in a relatively coarse microstructure in terms of Secondary Dendrite Arm Spacing (SDAS) and particle sizes [5], [6]. Boileau and Allison [7] have demonstrated the impact of the solidification rate on fatigue properties of A319 alloy and concluded that finer microstructures improve the fatigue resistance. Accordingly, alloys produced by LFC tend to have lower fatigue properties than DC alloys [8]. Shrinkage pores are more likely to appear during a slow cooling process and therefore LFC also tends to increase the number and the size of this pore category [9]. The detrimental effect of this kind of defects on the fatigue behavior of cast aluminum alloys has been the subject of many studies in the literature. It was shown that cracks frequently initiate at large pores located on the specimen

\footnotetext{
* Corresponding author at: INSA-Lyon, MATEIS, CNRS UMR 5510, 69621 Villeurbanne, France.

E-mail address: sebastien.dezecot@insa-lyon.fr (S. Dezecot).
}

surfaces or just below [10], [11], [12], [13]. Shrinkage cavities appear more critical than gas pores due to their more complex shapes [14]: it was shown for example in a AlSi7Mg0.3 alloy that fatigue cracks initiations correspond to the rupture of silicon particles located in the vicinity of the convex portions of the shrinkage pores. Silicon particles or intermetallic phases can also act as crack initiation sites when they are large compared to the pore size [6], [13], [15]. It is not clear, however, whether this is due to a size or a shape effect, in practice, large Si or intermetallic particles tend to have a more complex shape [16]. Those phases also have a strong influence on the crack propagation process, both on the crack paths and on the crack growth rate [6], [17], [18]. 2D surface characterization of damage by optical microscopy during thermomechanical fatigue has shown that the crack responsible for the failure always initiates from a shrinkage pore and propagates towards the intermetallic phases following a complex path strongly linked to the local phase distribution [3]. The detailed mechanisms which lead to fracture are however difficult to study with simple 2D/ surface observation as the microstructure of the material is complex and has a strong 3D character.

The aim of this work is thus to study in situ damage initiation and growth in a LFC aluminum alloy during cyclic mechanical loading at temperatures relevant for service conditions using X-ray synchrotron tomography. The severity of these loadings makes that the sample reduced areas is subjected to large scale yielding. 


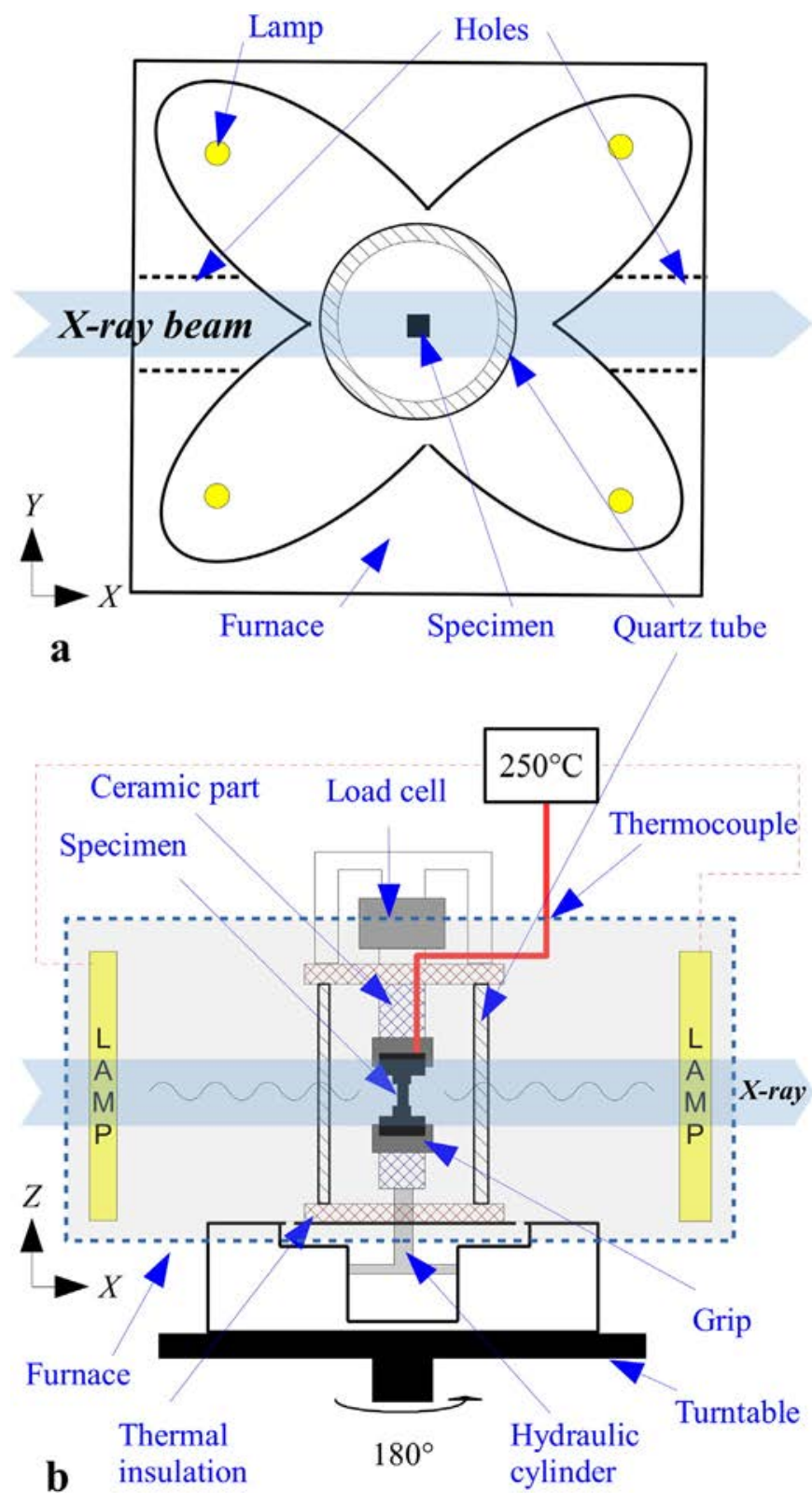

Fig. 1. Schematic drawing of the experimental setup : (a) top view of the furnace and (b) side view of the furnace with the fatigue machine.
The studied material is a LFC AlSi7Cu3Mg aluminum alloy commonly used for high temperature engine parts. To obtain samples which a microstructure that is representative of a cylinder head inter-valve bridge, samples were directly extracted from cylinder heads produced by the LFC process. The material has a relatively coarse grain structure (average grain size: $624 \pm 216 \mu \mathrm{m}$, SDAS: $76.1 \pm 9.4 \mu \mathrm{m}$ ). Before extracting the specimens by Electro Discharge Machining (EDM), the cylinder heads were overaged at $250{ }^{\circ} \mathrm{C}$ for $500 \mathrm{~h}$ to reach a stabilized precipitate state. During this heat treatment the material undergoes no solutionizing and the distribution of intermetallic particles remain as in the as-cast condition leading to large acicular interconnected Si eutectic particles with a Ferret diameter in the 1-100 $\mu \mathrm{m}$ range; other intermetallic particles are also irregular in shape and with a large size. Dumbbel-shaped samples are used for in situ fatigue testing. The square cross section is 2.1 by $2.1 \mathrm{~mm}^{2}$ after a final polishing with a $1 \mu \mathrm{m}$ diamond solution. Mirror polishing is necessary to avoid crack initiation on surface scratches but is also essential to remove the damaged layer of about $200 \mu \mathrm{m}$ which is created by EDM [19].

Although X-ray tomography has become an established technique to investigate damage during mechanical tests in structural materials [20] it has only been used recently to observe in situ propagation of fatigue cracks above room temperature [21]. In this work, a furnace has been designed and successfully combined with a fatigue machine used previously by some authors of this paper [20]. A compact $(25 \mathrm{~cm}$ square see Fig. 1) experimental setup has been designed and used on ID19 beamline at the European Synchrotron Radiation Facility (ESRF). The furnace is composed of four elliptical surfaces. One of their foci focused on the center of the specimen gage length. Four halogen lamps fixed on the second focal point of each ellipse allow to heat the sample by focusing the lamps radiation on the gage length (see Fig. 1) [22]. A water cooling system within the aluminum metallic walls of the furnace allows to efficiently dissipate heat and to obtain an outer surface temperature of about $25{ }^{\circ} \mathrm{C}$ at full power. Two diametrically opposite holes allow the X-ray beam to go through the furnace which is static. The fatigue machine and the specimen are free to rotate $\left(180^{\circ}\right.$ rotation $)$ during the recording of the radiographs. The load cell used should not be used above $70^{\circ} \mathrm{C}$ and thus it has been thermally insulated by an alumina insert. A 2 mm-thick quartz tube is used to transmit the load. Quartz has been chosen for its good mechanical properties at high temperatures (Young modulus above $73 \mathrm{GPa}$ at $400{ }^{\circ} \mathrm{C}$ [23]) and its ability to let the lamp light reach the sample: at least $90 \%$ of the signal (wavelengths ranging from 280 to $2000 \mathrm{~nm}$ ) is transmitted as it passes through vitreous silica [23]. Quartz also induces a reasonable and quasi constant attenuation of the X-ray beam during rotation. A preliminary calibration showed that the furnace design creates a quite wide (around $20 \mathrm{~mm}$ height) and homogeneous ( $\left.\mathrm{dT} / \mathrm{dz}<0.3{ }^{\circ} \mathrm{C} / \mathrm{mm}\right)$ hot zone, with temporal fluctuations lower than $1{ }^{\circ} \mathrm{C}$ per hour at $250{ }^{\circ} \mathrm{C}$. With this design, a
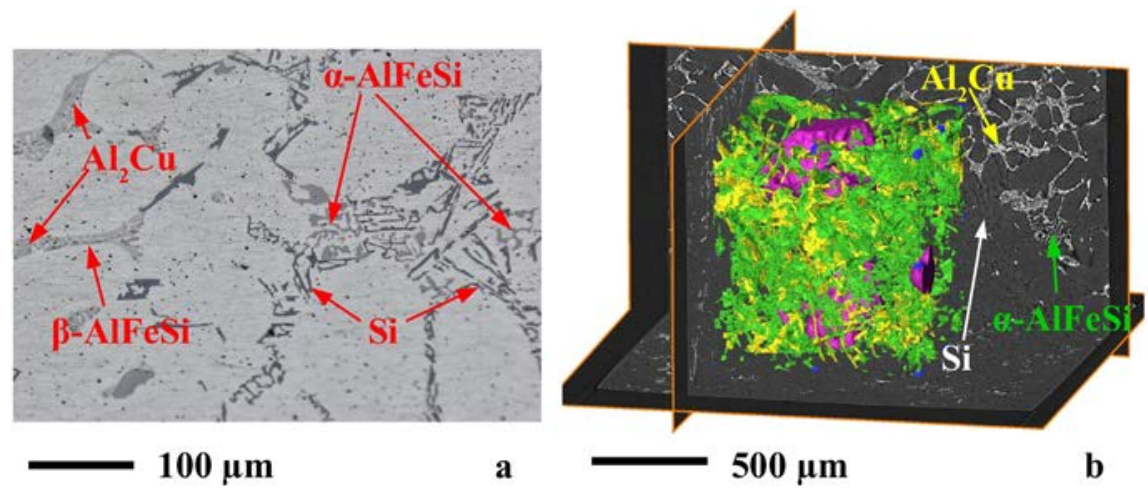

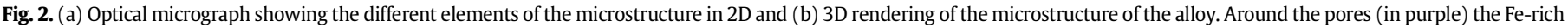

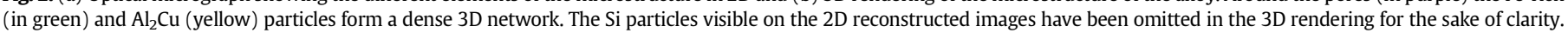
(For interpretation of the references to color in this figure legend, the reader is referred to the web version of this article.) 
rotation of the sample under load $\left(180^{\circ}\right.$; parallel beam) can be achieved. This rotation without missing views has the advantage of producing 3D volumes with very limited reconstruction artifacts contrary to missing angle tomography [21] and allows, for example to perform digital volume correlation on the reconstructed 3D images [24].

Uniaxial isothermal tensile fatigue tests at quasi constant stress amplitude (sew below) were performed in situ at $250{ }^{\circ} \mathrm{C}\left(\frac{T}{T_{f}} \approx 0.56\right.$ with $\mathrm{T}$ in Kelvin) with a load frequency of $0.1 \mathrm{~Hz}$, a load ratio of 0.1 and a maximum stress of the order of $140 \%$ of the yield strength in order to be in generalized plasticity as during low cycle fatigue (LCF) test. During the scans, the lower grip position is held constant. As the studied overaged aluminum alloy exhibits a viscous mechanical behavior above $150^{\circ} \mathrm{C}$ that induces creep or stress relaxation, CT scans are performed after a dwell time sufficiently long to reach stress and strain stabilization and avoid specimen displacements. After each scan, the lower grip position is adjusted in order to ensure a quasi constant stress amplitude all along cycling. CT scans were performed under load at minimum and maximum grips displacements. Images were obtained in pink beam mode (35 keV) with a CMOS PCO Dimax detector (2016 pixels ${ }^{2}$ ) with a detector/sample distance of $200 \mathrm{~mm}$. The scan duration for 2000 radiographs was $45 \mathrm{~s}$ with a $2.75 \mu \mathrm{m}$ voxel size. This short duration is also the key to help reducing creep deformation during the recording of the radiographs. The large spatial coherence of the ID19 beam allows to distinguish the eutectic silicon particles from the surrounding Al matrix thanks to phase contrast and also facilitates the detection of short cracks of few micrometers long [25] in spite of the moderate voxel size which was selected in order to image a $2 \times 2 \mathrm{~mm}^{2}$ cross section without resorting to local tomography.

Classical tomographic reconstructions using the filtered back projection algorithm reveal that high quality images can be obtained with this experimental setup confirming that creep of the sample during the scans is not an issue. As observed on 2D images (Fig. 2a), the 3D microstructure of the material consists in a complex 3D network of relatively coarse phases. Fig. 2b shows a 3D network of entangled very large particles (Silicon particles, $\mathrm{Al}_{2} \mathrm{Cu}, \alpha$-AlFeSi, $\beta$-AlFeSi) and pores. The various phases present in the alloy are clearly visible on reconstructed gray level images in the background. However, noise and the small difference between the gray levels of the different phases make automatic thresholding of the various phases difficult. Therefore, a Paganin algorithm [26] is used for reconstruction in order to obtain a better contrast between the different phases as shown in Fig. 3. It is important to note that the differentiation of $\mathrm{Al}_{2} \mathrm{Cu}$ and Fe-rich intermetallics remains complicated. A manual segmentation of these phases is required.

For the sake of clarity, the initiation of damage and its evolution during cycling can be described using vertical tomographic slices of the volume as shown in Fig. 3 where the mechanisms corresponding to initiation and propagation are illustrated. Two very large pores are visible in Fig. 3a. One has a quasi spherical shape (probably a gas pore) and the other with a much more complex shape is a shrinkage cavity. Secondary Fe-intermetallics and $\mathrm{Al}_{2} \mathrm{Cu}$ with a size relatively large compared to the width of the specimen $(2.1 \mathrm{~mm})$ are also visible.

The damage evolution during cycling can be described as follows:

- A crack appears in the vicinity of the shrinkage pore on a neighboring intermetallic particle $\left(\mathrm{Al}_{2} \mathrm{Cu}\right)$ after a few cycles (Fig. 3a). As illustrated in Fig. 3, the first crack initiates in the bulk and is therefore invisible from the surface.

Fig. 3. Reconstructed 2D slices showing the evolution of damage in the bulk of the sample ( $\sim 600 \mu \mathrm{m}$ below the surface) for different numbers of cycles: (a) 1 cycle, $\mathrm{F}=264 \mathrm{~N}$, (b) 20 cycles, $\mathrm{F}=268 \mathrm{~N}$, (c) 40 cycles, $\mathrm{F}=215 \mathrm{~N}$. The dashed line indicates schematically the location of the final crack. (d) Magnification of the initiation area after 2 cycles showing the location of the crack with respect to the local microstructure: a crack within a large $\mathrm{Al}_{2} \mathrm{Cu}$ particle located close to the convex part of a pore is observed; some cracked eutectic particles are also visible. The load direction is vertical. The labels on subfigure $a, b$, c show broken particles. Si particles: labels 1 and 4, $\mathrm{Al}_{2} \mathrm{Cu}$ : labels 2, 3 and 5.
- A progressive development of damage among the silicon particles is observed near the pores and/or at the crack tip (Fig. 3b).

- The crack links the different pores following the regions containing broken particles (Fig. 3c).
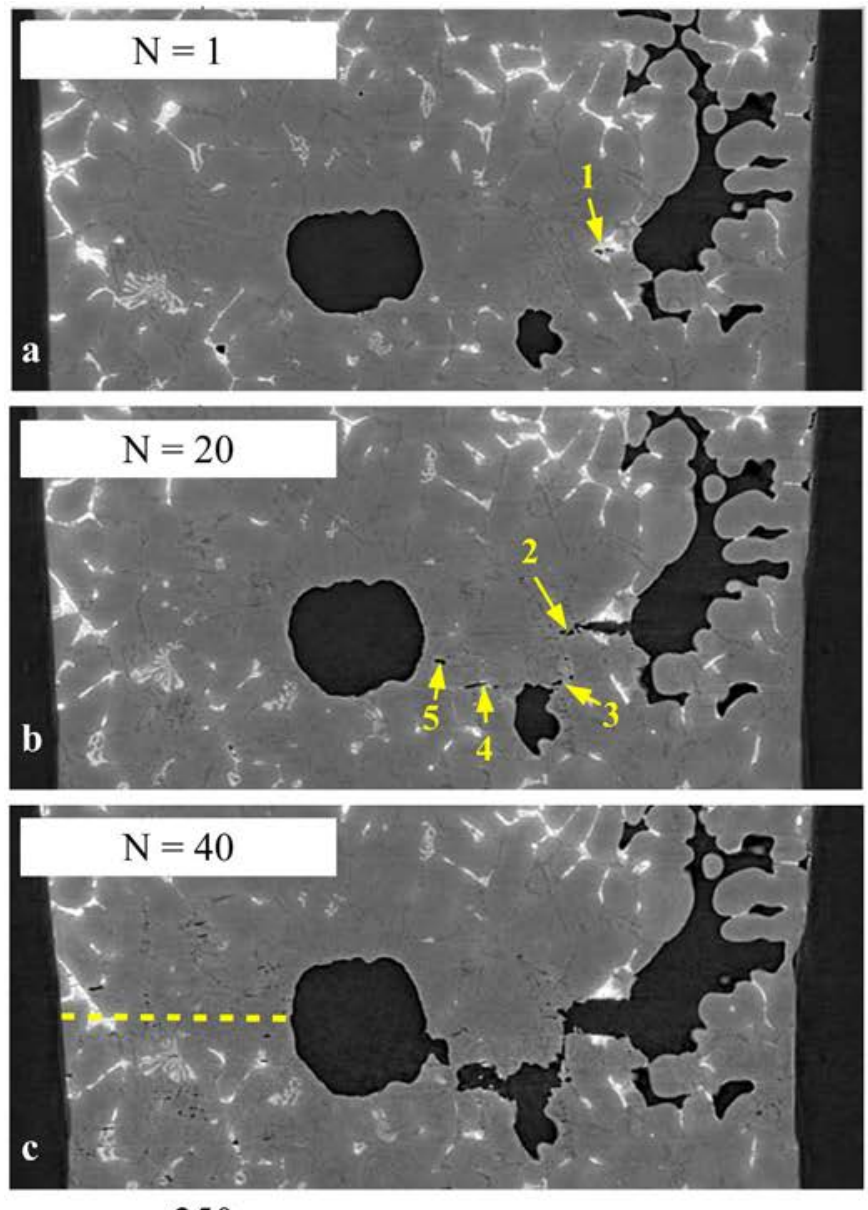

$250 \mu \mathrm{m}$

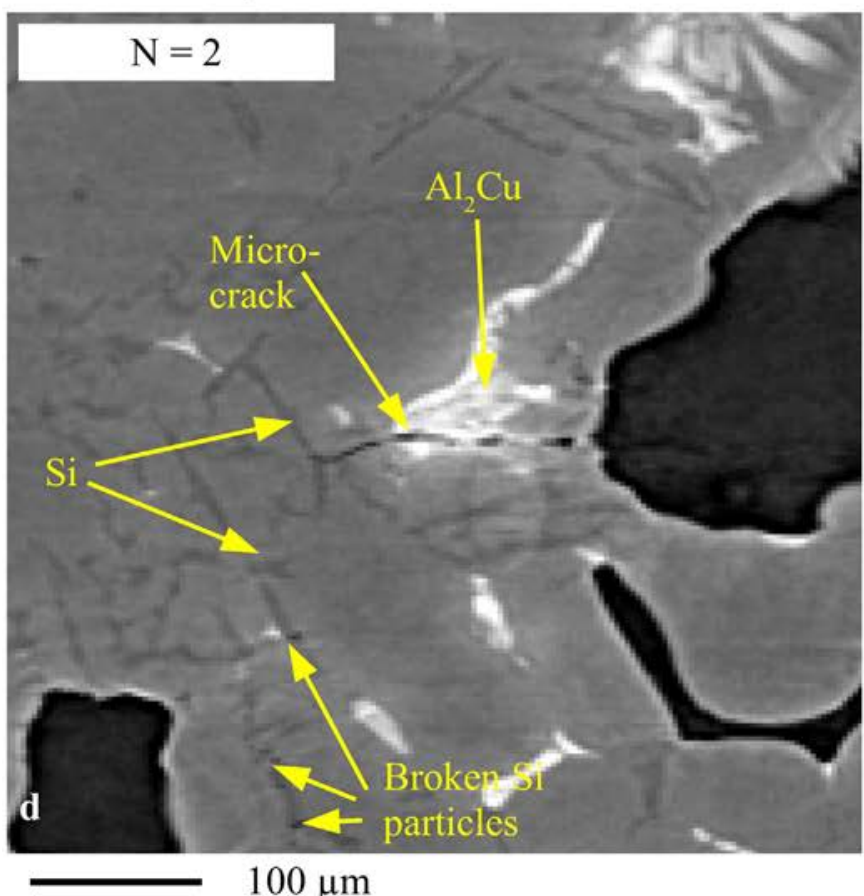

$100 \mu \mathrm{m}$ 

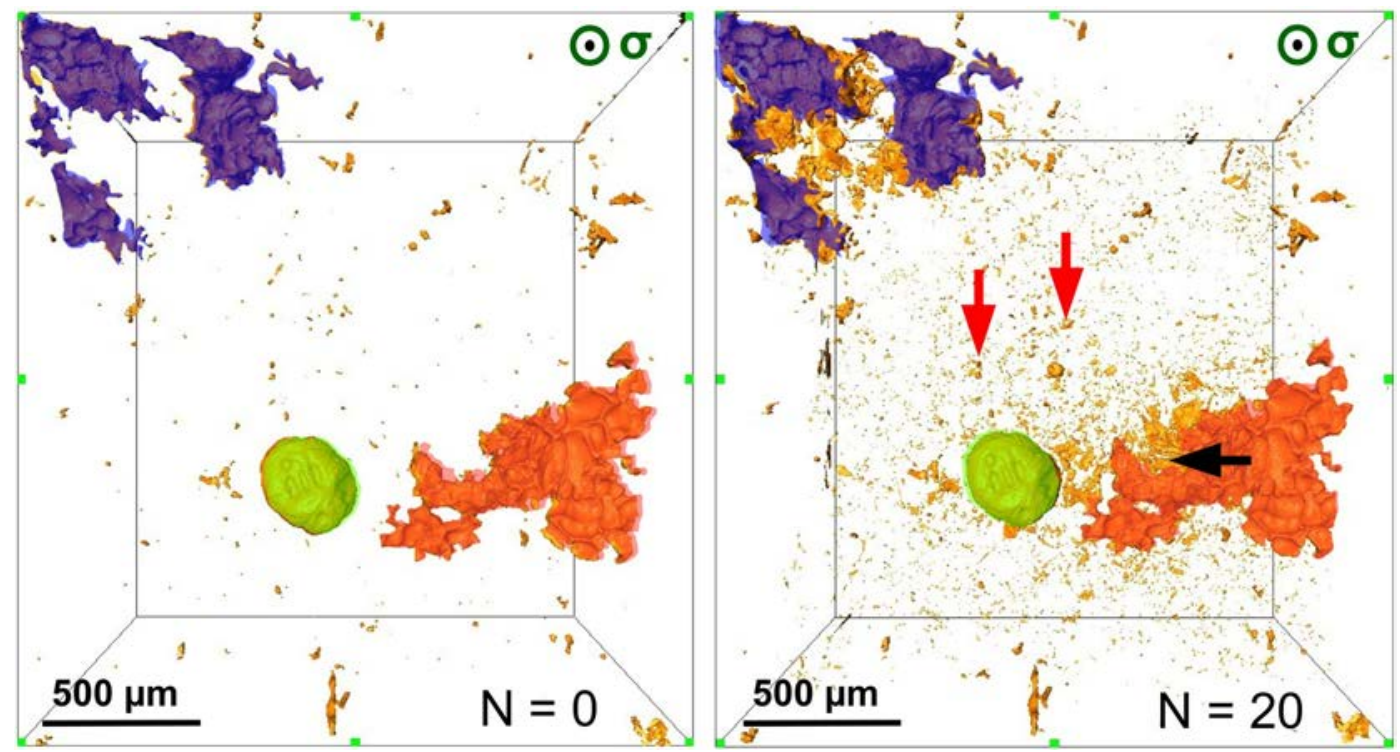

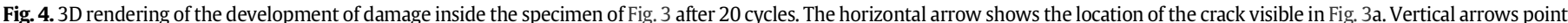

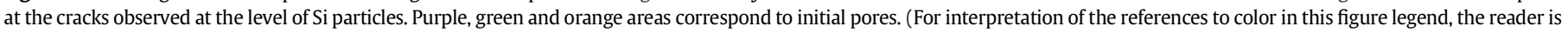
referred to the web version of this article.)

These mechanisms have been consistently observed on two other samples cycled at the same temperature and can therefore be considered as representative.

The fact that crack initiation occurs in the vicinity of a pore is clearly a result of the local stress concentration which exists at the periphery of those defects as pointed out by many authors [27], [28]. The much higher local curvatures of shrinkage cavities make those defects more critical than gas pores for crack initiation (see for example [29]). If an intermetallic particle is present in this stress concentration area, crack initiation occurs very rapidly by rupture of this particle. Gall et al. also explain that the rupture of secondary particles is due to the intense local plasticity and high level of triaxiality [30]. If this mechanism is well known for cast aluminum alloys the striking feature here is that initiation first takes place in the bulk (Fig. 4). In structural metallic alloys, internal crack initiations are usually observed in the case of Very High Cycle Fatigue. For materials with casting defects, in the case of fatigue lifes in the range of $10^{5}$ to $10^{7}$ cycles at room temperature, surface crack initiation dominates [29]. This might be due to the level of irreversible plasticity (the pre-requisite for crack initiation) which is easier at the surface than in the bulk. The experimental conditions investigated here lead to a quite different situation where a large plastic level is reached at the surface and in the bulk (LCF tests). Also, from a single topological argument, it is clear that the probability to find a brittle intermetallic particle close to a pore is larger in the bulk. Those two factors might account for the internal crack initiation which has been preferentially observed here.

The strain incompatibility between the aluminum matrix which has an elasto-viscoplastic behavior and the hard intermetallic particles (particularly Si particles) explain why those ones are prone to cracking during mechanical loading. The rupture of Si particles has been frequently observed, at the surface, inside the highly deformed area at the crack tip during High Cycle Fatigue tests [14], [31].Among all the particles, the elastic modulus of the Si particles is the one who diminishes the least when the temperature increases [32].

Unlike conventional cast $\mathrm{Al}$ alloys that are often studied after solution heat treatment, the LFC material studied here contains a network of large interconnected Si particles with platelet shapes [33]. Although those particles turn out to be brittle, they also have a reinforcing effect as they take up some load from the soft matrix as reported by Asghar et al. for an Alsi10Cu5Ni1 cast alloy [34]. A balance between this composite effect and the influence of the brittle phases on crack propagation should therefore be sought in order to improve the mechanical properties of the material in LCF conditions.

In summary, an experimental setup to study the in situ development of damage during fatigue tests for temperatures ranging between $200{ }^{\circ} \mathrm{C}$ and $300^{\circ} \mathrm{C}$ has been successfully developed. This setup was used in the case of a LFC cast aluminum alloy and it was found that:

- Coarse secondary particles ( $\mathrm{Si}, \mathrm{Al}_{2} \mathrm{Cu}, \alpha$-AlFeSi, $\beta$-AlFeSi) form a quasicontinuous network linking together large $(\sim \mathrm{mm})$ pores (mainly shrinkage pores).

- Crack initiation occurs on these particles via the stress/strain concentrations and high triaxiality due to the pores.

- Crack initiation invisible from the surface dominates contrary to what is generally observed for HCF. This might be due to the large level of plasticity induced in the samples, at the surface and in the bulk.

- Once initiated, cracks propagate through the 3D network of cracked secondary particles.

This work was funded by the French National Research Agency through the ANR project INDIANA (grant ANR-12-RMNP-0011). We thank E. Boller from ID 19 beamline at the ESRF for her efficient help during the experiment (proposal MA-2037).

\section{References}

[1] F. Szmytka, A. Oudin, Int. J. Fatigue 53 (2013) 82-91.

[2] M. Javidani, D. Larouche, Int. Mater. Rev. 59 (3) (2014) 132-158.

[3] S. Tabibian, E. Charkaluk, A. Constantinescu, F. Szmytka, A. Oudin, Int. J. Fatigue 53 (2013) 75-81.

[4] R. Venkataramani, R. Simpson, C. Ravindran, Mater. Charact. 35 (1) (1995) 81-92.

[5] R.E. Spear, G.R. Gardner, AFS Trans. 71 (1963) 209-215.

[6] Q.G. Wang, D. Apelian, D.A. Lados, J. Light. Met. 1 (1) (2001) 85-97.

[7] J.M. Boileau, J.E. Allison, Metall. Mater. Trans. A 34 (9) (2003) 1807-1820.

[8] S. Tabibian, E. Charkaluk, A. Constantinescu, F. Szmytka, A. Oudin, Fatigue Fract. Eng. M. 36 (4) (2013) 349-360, http://dx.doi.org/10.1111/ffe.12006.

[9] J.R. Brown, Met. Mater. 8 (10) (1992) 550-555.

[10] M.J. Couper, A.E. Neeson, J.R. Griffiths, Fatigue Fract. Eng. M. 13 (3) (1990) 213-227.

[11] Q.G. Wang, D. Apelian, D.A. Lados, J. Light. Met. 1 (1) (2001) 73-84.

[12] H.R. Ammar, A.M. Samuel, F.H. Samuel, Metall. Mater. Trans. A 473 (1) (2008) 65-75.

[13] S. Dezecot, M. Brochu, Int. J. Fatigue 77 (2015) 154-159.

[14] J.-Y. Buffiere, S. Savelli, P.-H. Jouneau, E. Maire, R. Fougeres, Metall. Mater. Trans. A 316 (1) (2001) 115-126

[15] H. Ye, J. Mater. Eng. Perform. 12 (3) (2003) 288-297.

[16] Z. Asghar, G. Requena, H. Degischer, P. Cloetens, Acta Mater. 59 (57) (2009) 4125-4132.

[17] F.T. Lee, J.F. Major, F.H. Samuel, Metall. Mater. Trans. A 26 (6) (1995) 1553-1570. 
[18] L. Zeng, J. Sakamoto, A. Fujii, H. Noguchi, Eng. Fract. Mech. 115 (2014) 1-12.

[19] S. Kumar, R. Singh, T.P. Singh, B.L. Sethi, J. Mater. Process. Technol. 209 (8) (2009) 3675-3687.

[20] J.-Y. Buffiere, E. Maire, J. Adrien, J.-P. Masse, E. Boller, Exp. Mech. 50 (3) (2010) 289-305.

[21] T. Chapman, K. Kareh, M. Knop, T. Connolley, P. Lee, M. Azeem, D. Rugg, T. Lindley, D. Dye, Acta Mater. 99 (2015) 49-62.

[22] A. Koster, E. Fleury, E. Vasseur, L. Remy, ASTM Special Technical Publication, 12311994 563-580.

[23] N.P. Bansal, R.H. Doremus, Handbook of Glass Properties, Elsevier, 2013.

[24] N. Dahdah, N. Limodin, J.-F. Witz, R. Seghir, E. Charkaluk, J.-Y. Buffiere, Strain (2015) submitted for publication.

[25] J.-Y. Buffiere, E. Maire, Imagerie 3D en mécanique des matériaux, Lavoisier, 2014.

[26] D. Paganin, S.C. Mayo, T.E. Gureyev, P.R. Miller, S.W. Wilkins, J. Microsc. 206 (1) (2002) 33-40.
[27] I. Serrano-Munoz, J.-Y. Buffiere, C. Verdu, Y. Gaillard, P. Mu, Y. Nadot, Int. J. Fatigue, http://dx.doi.org/10.1016/j.ijfatigue.2015.07.032.

[28] Y. Amirirad, A. Afkar, L. Wisweh, Int. J. Adv. Manuf. Technol. 74 (9-12) (2014) 1469-1485.

[29] Ph.D. thesis. I. Serrano-Munoz, Institut National des Sciences Appliquã@es de Lyon, 2014.

[30] K. Gall, N. Yang, M. Horstemeyer, D.L. McDowell, J. Fan, Fatigue Fract. Eng. M. 23 (2) (2000) 159-172.

[31] K. Gall, N. Yang, M. Horstemeyer, D.L. McDowell, J. Fan, Metall. Mater. Trans. A 30 (12) (1999) 3079-3088.

[32] C.-L. Chen, A. Richter, R.C. Thomson, Intermetallics 18 (4) (2010) 499-508.

[33] S. Shivkumar, L. Wang, D. Apelian, JOM-J. Min. Met. Mat. S. 42 (11) (1990) 38-44

[34] Z. Asghar, G. Requena, E. Boller, Acta Mater. 59 (16) (2011) 6420-6432. 